\title{
Sustainable Transport Strategies: A Case Study of Riyad, Saudi Arabia
}

\author{
Gaydaa Al Zohbi* \\ Department of Mathematics and Natural Sciences, Prince Mohammad Bin Fahd University, Al Khobar, Kingdom of Saudi Arabia
}

\begin{abstract}
Transport is considered as an important action zone for achieving sustainable development since it takes a significant part in the economy sector with its existence among the production pattern, at geographic ladder [1]. Although, it is evident that the transport sector is responsible for many environmental issues. Riyad city is suffered from severe pollution caused by extensive use of motorized transport. Thus, implementation of appropriate policy tools relieve the harmful effect of transport activities by attaining sustainable transport. This paper pursues to evaluate the sustainability situation of transportation sector in Riyad city by using real data. The current paper ended with some recommendations to achieve sustainable transportation in KSA. Results indicated that the increase of car ownership and travel demand, the low use of public transport, and the rise of air and noise pollution level and the high level of road mortality lead to make the transportation system of Riyad unsustainable. On the other hand, the Saudi government have already started to execute many planned projects to achieve sustainable transportation such as the metro and bus network in Riyad and the installation of charger station of electric vehicle. In addition, the Saudi government set out many policies and target such as Target 11.2 that aims to achieve sustainable transportation in KSA and Target 3.6 that intents to minimize the high mortality rate from road accidents.
\end{abstract}

\section{Introduction}

Transportation system and infrastructure are the main stone of urbanization. The concept of urban transport is connected with the urban shape and locative structure. Meanwhile, urbanization is planned in accordance with the evolution of the capacity and efficiency of urban transport systems. Currently, urban transportation gets more attention and is considered as major pillar in propping the mobility of commuters in cities that register an expand of its areas and rising in the population. However, the transportation in urban areas is characterized by complicated and intricate caused by many factors such as the quantity and diversity of traffic and the plurality of origins and destination. It is vastly admitted that the present transportation system is unsustainable almost in the worldwide.

The Kingdom of Saudi Arabia is considered among the most urbanized countries worldwide, statistics showed that eight over ten people living in urban area. The urbanization, industrialization, growth of population, climate conditions and the abundance of fuel in Saudi Arabia lead to an excessive use of motorized transport. Moreover, the transportation sector in Saudi Arabia uses nearly a quarter of its total energy, and the consumption levels are projected to rise in coming years. Thus, many environmental and social issues are produced. These issues affect the urban life quality, the ecosystem and the human health and its productivity by increasing the level of air and noise pollution, congestion and traffic accidents. Therefore, the incorporation of sustainability into transportation designing plan is an insistent request. The notion of sustainable transportation arises from the concept of sustainable development in the sector of mobility and is defined as the capacity to prop the mobility requirement with the least harmful to the environment and the least influence of the mobility requirements for future generation.

The purpose of the present paper is to assess the sustainability of the current situation of transportation in Riyad city. Riyad is the capital and the largest city of the Kingdom of Saudi Arabia with a population of 6,506,700. It is the political, administrative and financial center of the KSA. The assessment is performed by using range of indicators to perform an impact-based analysis of transport activities. The framework of these indicators are based on environmental, social and economic dimensions. The study is realized using real data on the situation of transport systems and policies, infrastructure, urban development and environmental degradation caused by transportation. Finally, some recommendations to achieve sustainable transportation in Riyad are highlighted.

\section{Overview of Riyad'urban development}

\footnotetext{
* Corresponding author: galzohbi@pmu.edu.sa
} 
Riyadh was a traditional Arabic town in 1902 with a population less than 19,000 people in an area of $1 \mathrm{~km}^{2}$ [2]. In 1931, the first phase of transformation of the city happened in the era of the King Abdul-Aziz Al-Saud, where he announced Riyadh as the capital of modern Saudi Arabia. During the first phase, the city started growing and attained an area of $13 \mathrm{~km}^{2}$ with a population of 83000 people. The second phase occurred in 1950, over the growth of the oil sector, the city became openable and extrovert [2]. Since the urbanization of the city was amorphous and not well striped, authorities recognized the need of city code to control the urban development. The first master plan was performed in 1960 by Doxiadis Associates, a Greek architect consultation organization. However, the first plan was failed caused by the unexpected growth that outstripped the urban planned borders. Hence, a second master plan was made and it flopped also. During the explosive oil growth of the early 1970's, Riyad experienced huge changes in its population and urban growth, that exceeds the city borders determined by Doxiadis plan, caused by the pointedly increase of the government expenditure. Hence, a revision and update of Doxiadis plan were required to deal with the city's enormous expansion. In 1976, the SCET International/SEDES of Paris was requested to carry out the revision of Doxiadis plan with a focus to develop an adjusted expansion and phasing plan. In 2003, a Comprehensive Riyad Strategic Plan (CRSP) founded by Arriyadh Development Authority (ADA) and comprised all motif of city growth like urban, transportation and economic. The CRSP pointed urban growth to a specified areas by determining urban growth boundaries (UGBs) [3]. The aim of UGBs was to guide and restrict the urban growth to specify geographic area over a specified period of time. In 2015, the rise of oil prices procured to quick growth rate in Riyadh. This growth rate caused social, environmental and economic issues.

The urban growth phases in Riyadh city is displayed in Table 1 and Figure 1. It can be seen that a huge increase in the total city area from $1755.2 \mathrm{~km}^{2}$ to 3131.4 $\mathrm{km}^{2}$ has been recorded between the pre-phase 1 and phase 4. This is an obvious evidence that Riyad is expanding quickly. The rapidly urban expansion contribute to create an unsustainable environment by increasing roads length, driven distance, vehicles number, fuel consumption, greenhouse gases emission and pollution, and ecological modification.

Table 1. Riyadh urban growth phases

\begin{tabular}{|l|l|l|l|}
\hline $\begin{array}{l}\text { Urban Growth } \\
\text { Phase }\end{array}$ & $\begin{array}{l}\text { Year } \\
\text { started }\end{array}$ & $\begin{array}{l}\text { Area } \\
\left(\mathbf{k m}^{2}\right)\end{array}$ & $\begin{array}{l}\text { Total City } \\
\text { Area }\left(\mathbf{k m}^{\mathbf{2}}\right)\end{array}$ \\
\hline Pre-phase 1 & 2005 & 1755.2 & 1755.2 \\
\hline Phase 1 & 2010 & 642.7 & 2397.9 \\
\hline Phase 2 & 2015 & 365.3 & 2763.3 \\
\hline Phase 3 & 2020 & 292.2 & 3055.4 \\
\hline Phase 4 & 2025 & 75.9 & 3131.4 \\
\hline
\end{tabular}

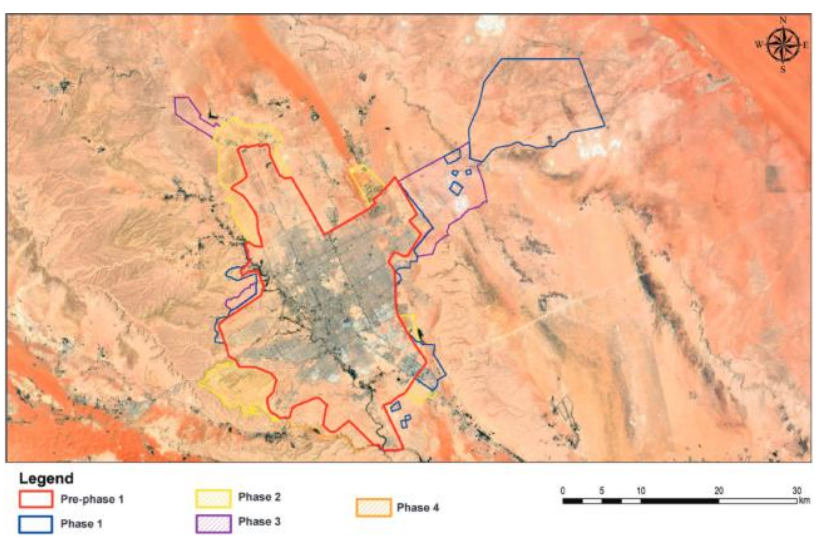

Fig. 1. Riyadh urban growth phases [4] .

Figure 2 set out the population and the growth rate between 2000 and 2020. The population increased from 3567000 to 7231000 between 2000 and 2020 with an average growth rate of $3.58 \%$ year. The relationship between population density and sustainability is complicated and involved many environmental, social, physical and attitudinal agents. In addition, viewpoints on population density and sustainability change from nation to nation and from city to city in the same country. Cities with high population and urban densities are characterized by the most effective, active, diversified and ecologically sustainable [5]. On the other hand, cities with low population density are considered as sustainable due to spacious living areas, less air polluted, more availability of land to construct houses and outdoor space [6]. However, the fall of population density has a deep trace on environmental sustainability. A rise of mobility demand causes an increase of energy consumption and environmental deterioration, increase of the cost of basic services, and reduce the urban productivity.

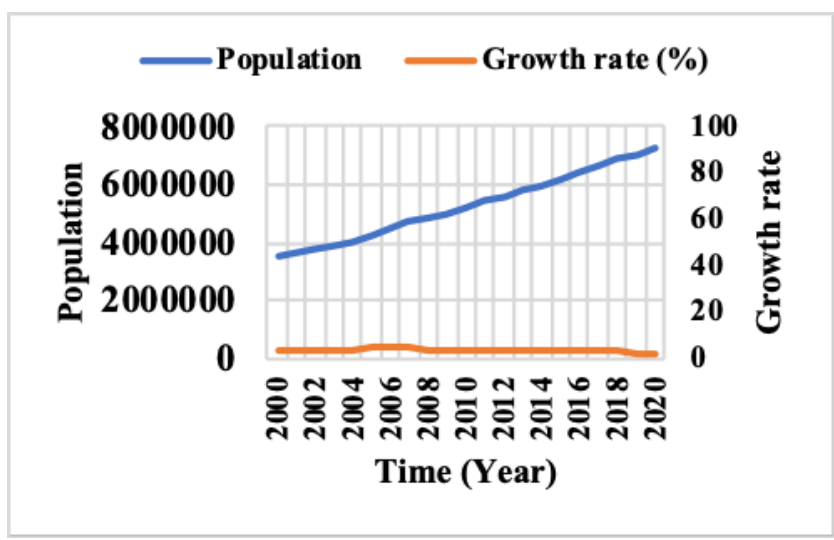

Fig. 2. Riyadh's metropolitan population and growth rate for the last 20 years [7]

\section{Indicators of sustainable transport}

Indicators are measurable characteristics used to asses advance toward goals. Transport is an essential element in the framework of sustainable development due to its impact on economy, environment and society. A sustainable transport aims at minimizing environmental issues, improving life quality and enhancing social 
inclusion, and aiding in creating more efficient economy (Figure 3). The indicators of sustainable transport can be classified into three categories:

- Social indicators: comprises the status of human health, equity and community livability. Sustainable transport intends to meet safely the basic access needs of individuals, achieve an affordable transport, and to offer many transport mode choices.

- Environmental indicators: includes the estimation of various kinds of pollution (air, water and noise), wildlife death caused by vehicle collisions. Sustainable transport aims to limit greenhouse gases emissions and waste, reduce non-renewable energy consumption, reduce noise and land use. In addition, it intends to increase the use of fuel efficient vehicles, turn into green fuels and enhance and ameliorate energy efficient modes such as telework, cycling, and walking.

-Economic indicator: it aims to monitor the performance of the transport system and the costs and benefits for the community and person. In addition, it aims to assess the economic effects on transport policies

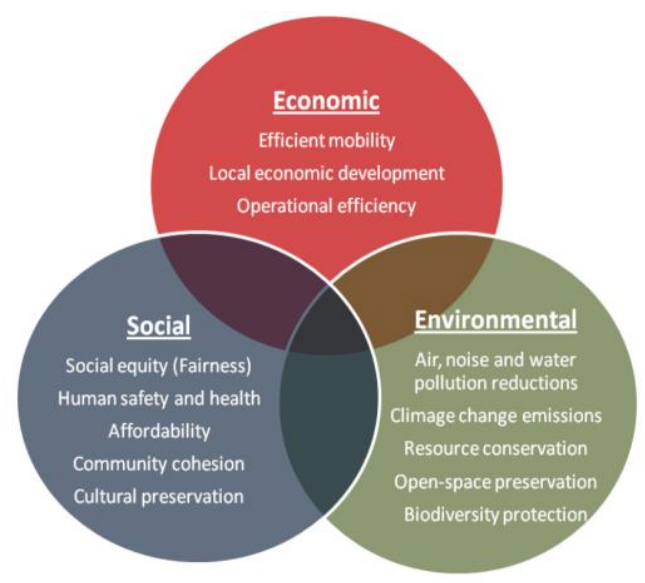

Fig. 3. Sustainability dimensions and aspects [8]

\section{Current situation of transportation in Riyad}

\subsection{Evaluation of Transportation and Infrastructure Systems}

The penetration of vehicles in the transportation system of Riyadh has been started in 1950s and is intensified in the 1970s with the growth of population and economy caused by the oil boom. The total number of vehicle raised between 1968 and 1999 from 26,880 to 670,300 and an increase of the average automobiles ownership per home by two and half times has been recorded during the same period [9]. The vehicles were the main transportation mode in the Doxiadis Master Plan. Thereby, streets are planned in hierarchical pattern, that involved expressways, highways, freeways, arterial street, collector and local streets [10]. The rise of car ownerships and reliance on mobilized transportation in Riyad make the path toward the achievement of sustainable transportation very long.

\subsection{Travel demand and modal split}

Riyad is the capital of the Kingdom and, has examined an enormous population and an economic evolution. Currently, it is the economic center of the Central Region and the biggest metropolitan area in the country. Hence, it represents the political, economic, and cultural center for the Kingdom and a significant center for internationals and regional commerce and communication. The enormous growth of economy and population led to a tremendous increase in mobility and transportation demands and therefore raise the number of car use and car ownership. Then, the need to build highways and arterial ways over the city increases.

The growth of population and vehicles number between 1968 and 2019 in Riyadh are shown in Figure 4. It can be observed that the population recorded a tremendous increase between 1968 and 2019 and it conducts to a significant rise in vehicle number.

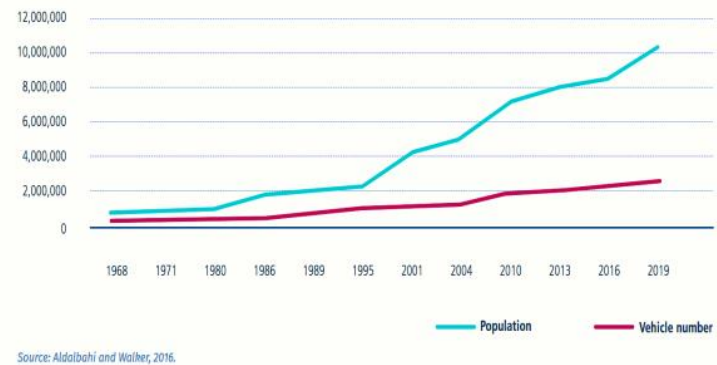

Fig. 4. Vehicle number and population and in Riyadh between 1968-2019.

The main transportation method to go to work and schools is Riyad is displayed in Figure 5. It can be observed that $91 \%$ of the people use car to go to work and schools while less than $1 \%$ use bus. Meanwhile, the availability of car parking in Riyad conducts to increase car trips and support car ownership. In average, there is $2.1 \mathrm{~m}$ of road per person, including 1833 parking spores for every 1000 persons in the central Business District [11].

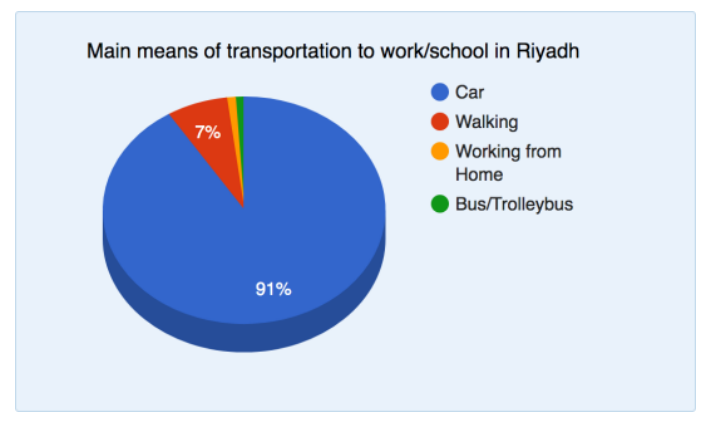

Fig. 5. Main means of transportation to work/school in Riyad [11] 


\subsection{Road network and mobility}

The change of traffic properties in Riyad between 1998 and 2024 is displayed in Table 2. It can be observed that a tremendously increases of the total number of road trips is recorded between 1998 and 2023. In addition, the average length of the trip increases from $10.6 \mathrm{~km}$ in 1998 to $14.2 \mathrm{~km}$ in 2009 and it will increase to 17.2 in 2024. This can be explained by the huge urban expansion of Riyad city. Besides, the average duration of the trip increases from 11.8 minutes in 1998 to 20.2 minutes in 2009. It is caused by the urban expansion and the high congestion level in Riyadh.

This change of traffic properties in Riyad city led to increase the roads network that requires a rise in highways building. The increase of car ownership and the rise of road network can affect the landscape and the ecosystem, increase the traffic congestion, reconfiguration of local topography and increase air, land and noise pollution. In addition, the Kingdom suffers from high traffic mortality rate, and is counted among the 10 leading countries in high traffic mortality in the world. Evidence shows that the bill of road traffic accidents is very high and it costs 21 billion SAR yearly [12]. It can be noticed that the transportation system is unsustainable in Riyad.

Table 2. Change of traffic properties in Riyad over the time [12]

\begin{tabular}{|l|l|l|l|}
\hline \multicolumn{1}{|c|}{1998} & \multicolumn{1}{|c|}{2009} & \multicolumn{1}{c|}{2024} \\
\hline $\begin{array}{l}\text { Total number of } \\
\text { road-trips }\end{array}$ & $\mathbf{4 , 4 5 8 , 5 2 3}$ & $\mathbf{6 , 5 9 7 , 9 7 6}$ & $15,047,901$ \\
\hline $\begin{array}{l}\text { Total distance } \\
\text { traveled by car }\end{array}$ & $\mathbf{9 3 , 3 4 1 , 0 0 0}$ & $\mathbf{2 5 8 , 2 3 1 , 0 0 0}$ & $\mathbf{4 7 4 , 4 3 3 , 0 0 0}$ \\
\hline $\begin{array}{l}\text { Average length } \\
\text { of the trip (km) }\end{array}$ & 10.6 & 14.2 & 17.2 \\
\hline $\begin{array}{l}\text { Average } \\
\text { duration of the } \\
\text { trip (minutes) }\end{array}$ & 11.8 & 20.2 & 37.2 \\
\hline $\begin{array}{l}\text { Average speed of } \\
\text { the transition } \\
\text { (km/h) }\end{array}$ & 54 & 42 & 27 \\
\hline
\end{tabular}

\subsection{Congestion}

Riyadh city experiences high traffic congestion even without any causes, it is persistent all the time and intensified on highways [13]. Many factors lead to the high traffic congestion such as the high number of vehicle ownership in KSA that exceeds 200 per 1000 persons. Saudi Arabia ranked first in the vehicle importer in the Middle East with a $40 \%$ of all vehicle sold to the Middle East. In addition, the under use and the absence of public transport, and the low petrol price lead to increase the energy consumption and the level of traffic congestion.

The Kingdom of Saudi Arabia recorded a high number of mortality from Road Traffic Accident (RTAs) with 32:1 accident to death ratio. In addition, road injuries are described as the most grave with an accident to injury ratio of $8: 6$. Besides, RTAs are considered as the major cause of death of old male with age between 16-30 years old, which ranks the country 32 in the world [14].

Figure 6 displays the change of traffic congestion in Riyad between 1996 and 2021. It can be seen that the overloaded increased tremendously from $10 \%$ to $67 \%$ and the not congested decreased from 38\% to $7 \%$ between 2006 to 2021. The congested arterial increased between 1996 and 2006 and then it will decrease in 2021. It can be concluded that the situation of urban transportation become aggravated and a comprehensive solution must be brought.

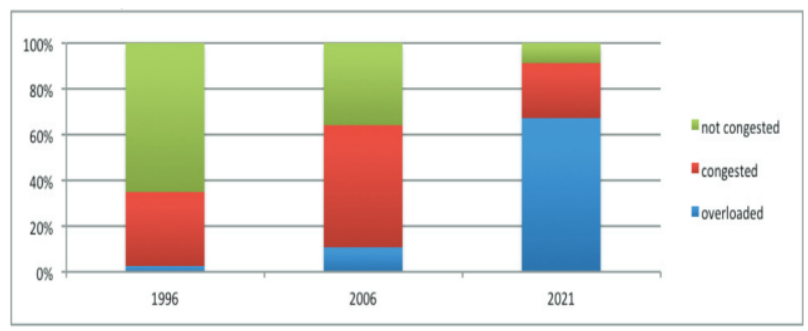

Fig. 6. Overloaded, congested and non-congested Arterials in Riyadh 1996 to 2021 [13]

\subsection{Public transport}

The use of public transport in KSA is very insignificant and people use private cars for transportation intercity and intracity since it is counted as the fastest and more convenient choice. The public transport is managed by the Saudi Arabian Public Transport Company (SAPTCO), established in 1979 with a government subsidy and it links upwards of 282 cities and villages over the kingdom and it supplies intercity and intracity networking. SAPTCO is characterized by bad efficiency, low bus loading and finite availability to bus services in urban areas. Besides, it faces competition from unregulated buses operated by entrepreneurial individuals knows as jitneys.

The use of public transport in KSA confronted many economic, social, climate and regulatory challenges. For the regulatory challenges, the shortage of public transport infrastructure, and the convenient policies and laws to support transferring demand from private transport modes to public transport modes lead to underuse of public transport. In addition, the lack of financial attractiveness and government subsidy for public transport and the affordability of owning private car due to the low fuel price and the effortless to own car in the kingdom lead to a preference of using private cars. Moreover, many social challenges affect the use of public transport such as the absence of conscience and awareness on the advantages of public transport, and the high preference of using private car due to the social status linked with car ownership. Further, for the Saudi residents, the public transport is dedicated for the foreign blue-collar workers. The massive economic growth attracts migrants from many countries. However, a new strategy has been launched by the government and is based on the replacing of foreign worker with Saudi workers and it is known as Saudization. Thus, travel 
attitude will be changed and the number of daily journey will rises. After a longstanding ban, the decision has been taken and women are authorized to drive since June 2018. Therefore, the car ownership and the daily trip has been increased. The climatic conditions are also considered among the parameters caused an increase of car use in Riyad city. The city follows the desert climate and is marked by hot summer with very high temperature that reaches $57^{\circ} \mathrm{C}$. Consequently, the number of trip by walking and by using non-motorized transport reduce. Moreover, the lack of pedestrian facilities in Riyad, the overcrowding of street and the difficulty to cross roads decreases walking as mode transport [15].

\subsection{Environmental Deterioration}

The noise maps measured and GPS data for Riyad city has been developed by [16]. Results indicated that Riyad city is experienced a significant noise pollution caused mainly by road traffic. A monitoring study of traffic noise in 42 sites in 13 areas in Riyad city has been conducted by [17]. Finding showed that more than half of the total sample population suffered disturbance caused by urban traffic noise. For $40 \%$ of the sample population, the maximum level of recorded disturbance attained through the evening/night hours while the traffic noise was always disturbing for another $12 \%$. In addition, it has been found that there are many factors aggravate the degree of urban traffic noise in Riyadh such as high speed, overloading, poor maintenance of vehicle exhaust and disobedience of traffic regulations and rules.

An investigation study of the air pollutants in Riyad city has been carried out by [18]. Results indicated that air is polluted mainly by PM10 (74\%) and SO2 (24\%), pose the most significant impendence on denizen city in Riyadh. However, the impact of $\mathrm{O}_{3}$ and $\mathrm{CO}$ on air quality is very restricted. In addition, it has been found that the highest PM10 pollution has been recorded in the southeast of the city and the lowest is in the northeast. Whereas, the lowest $\mathrm{SO}_{2}$ pollution is registered in the southeast and the highest is registered in the northwest. Moreover, results indicated that $75.35 \%$ of the air in the north east of Riyad is clean which make it the cleanest and the healthiest air quality in Riyad. The main sources of $\mathrm{SO} 2$ emissions is fossil fuel burning and the main source of PM10 is from automobile emissions, dust and cooking smoke. It can be conclude that the transportation is one of the main causes of pollution in Riyadh. Another study to measure the concentration of PM10 and PM2.5 in Riyad airport (a suburban area) and in King Fahad road district (urban area) located in Riyadh during a period of 22 months, from January 2012 to October 2013 has been conducted by [19]. Results revealed that the AQI values overtook 100 during 6 months in Riyad airport, whereas it surpassed 100 during all month at King Fahad road district.

The conducted studies on the noise and air pollution in Riyadh emphasize the fact that the urban transportation considered as veritable threat on environment, quality of life and health human.

\subsection{Transport Policies}

The transport sector in KSA is administrated by many governmental bodies, involving the Ministries and national authorities such as Ministry of Transport, Public Transport Authority and the General Administration for traffic. In addition to the governmental bodies, Riyad has Ar-Riyad Development Authorities that works on amelioration and development of the urban plan of the city, providing the substantial public services, conducting strategic urban studies and pursuing the development programs implemented by the government.

In the framework of the vision 2030, the Kingdom endorses many programs and projects that aim to attain the goals of sustainable development in its three pillars. The kingdom planned to reach two targets that are directly linked to sustainable transportation. Target 11.2 intents to ensure an affordable, accessible, sustainable and safe transport for all, and to ameliorate safety of roads by enlarging public transport that can be convenient to those in vulnerable situation such as, children, elderly person and person with special needs. The second target is Target 3.6 and it pursues to bisect the number of total dying and wounded from road accidents. The realization of these goals contributes to accomplish the integration of sustainability in transportation system in Riyadh.

\section{Developed projects in the transportation system of Riyad}

\subsection{King Abdul-Aziz project for Riyad public transport system}

The King Abdul-Aziz project will be the largest public transport infrastructure project worldwide and it aims to reduce the problem caused by congestion and pollution. The goal of this project is to develop and construct metro network, a bus system and other transport services, serving major attractions in Riyadh such as universities, airport, commercial areas and activity corridors. This project is designed for a maximum capacity of 4.5 million passengers per day and it comprises six lines of trains network with a total length of $179 \mathrm{~km}$ and 22 lines of bus network with a total length of 1,900 km (Figure 7).

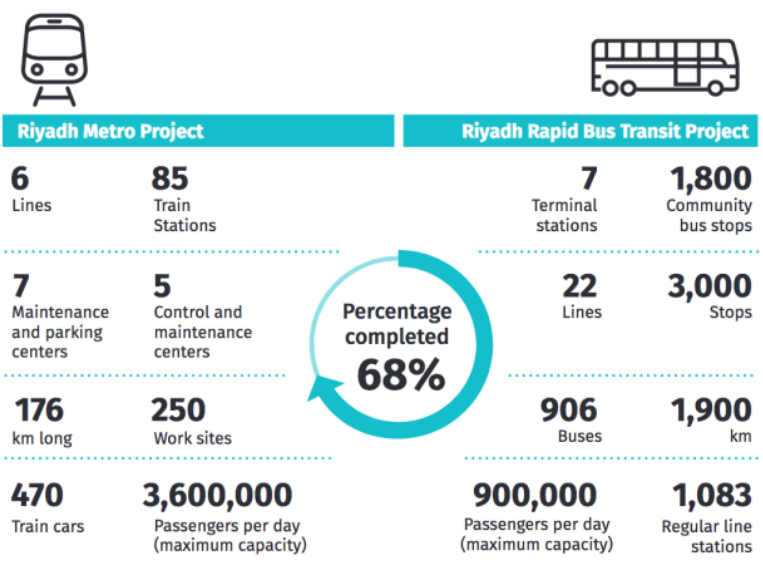

Fig. 7. King Abdul-Aziz project for Riyad public transport system 


\subsection{Municipal spaces planning}

The Riyadh Municipality has planned to implement municipal and open spaces, and pedestrian walkways in order to enhance the quality life of citizens by improving environment, health, wellness and social. Municipality square with an area of $700000 \mathrm{~m}^{2}$ and nine open spaces with an area of $47,000 \mathrm{~m}^{2}$ have been implemented. Also, four municipal spaces with an area of $100,000 \mathrm{~m}^{2}$ and 8 open sources with an area of $50,000 \mathrm{~m}^{2}$ are under construction. In addition, 58 pedestrian walkways in developed sites and 60 pedestrians walkways around the gardens have already realized and 6 more are under construction.

\subsection{Electric and hybrid Vehicles in Riyad}

The Kingdom installed the first commercial charging station for electric vehicles in Riyad in 2019 and more stations are anticipated to be set up. The increase of charging stations will promote the citizens to use electric vehicle. Meanwhile, the Saudi government authorized the importation of electric vehicle for own use. In addition, The use of hybrid vehicle become popular in the Kingdom. Thus, Riyad has been started already to take action in order to achieve sustainable transportation. However, the consumer acceptance to hybrid and electric vehicles faces many challenges. The cost of hybrid vehicle is higher than non-hybrid vehicle of the same level and the higher price of additional electrical components and their maintenance and replacement, such as the battery, lead to low demand. Besides, the technicians and maintenance tools are still not available. Moreover, the misconception and lack of information regarding the hybrid vehicle technology misguide the consumers. Moreover, the low fuel cost in the Kingdom discourages the use of hybrid cars.

\subsection{Green fuel}

An accord has been signed between ACWA power international, Air Products \& Chemicals and the kingdom's planned futuristic city of Neom to establish $\$ 5$ bn hydrogen-based ammonia plant generated by renewable energy, to be operated in 2025 . The project aims to generate 1.2 million tons of green ammonia yearly, using four gigawatts of wind and solar energy. Besides, it will generate nitrogen and 650 tons of hydrogen daily [13]. The technique used to produce green ammonia is carbon free, which help reducing the greenhouse gas emissions. The green ammonia is used as transport fuel for fuel cell vehicles, green fertilizer, industrial energy sources and energy storage for long time. In addition, the infrastructure of production and distribution is mature. Air Products will be the "exclusive off-taker" of the green ammonia, which will be exported around the world to produce green hydrogen for the transportation market.

\section{Conclusions}

An evaluation of the sustainability of transport system in Riyadh city has been carried out in this study. Results showed that Riyad experienced a tremendous urban expansion, huge population rise, enormous increase of vehicle number and immense augmentation of road transport infrastructure. These modifications generated many issues such as congestion, air and noise pollution, and high death rate from road accident. Thus, the transportation system in Riyad city is still far to become sustainable due to many reasons related to the rise of car ownership, low use of public transport, high mortality rate from road accidents, persistent rise of travel demand since Riyad is the capital and is considered as political, commercial, administrative center for the Kingdom. Moreover, the scarceness of cycling and walking infrastructure, the urban design of the city that relies on vehicles for transportation, and the desert climate of the city discourage the walking and cycling.

On the other hand, the Saudi government, through its vision 2030, have planned to execute many projects that boost the efforts needed to implement the main pillars of sustainability in the transportation system of Riyadh. The most important project is the development and construction of public transport system for Riyadh that comprise metro and bus networks and the implementation of charger stations of electric vehicles in Riyad. Besides, two targets have been set out in the framework of the Saudi's vision 2030 in order to achieve sustainable transportation in the Kingdom.

It should be pointed out that more action should be taken from the government related to the development of new projects and enactment of new laws and policies to stimulate the efforts toward attaining sustainable transportation. Meanwhile, the rising awareness of the importance of achieving sustainable transportation among citizens and involving them in activities to promote sustainable transportation solutions.

\section{Solution and recommendations}

Sustainable transportation refers to an efficient transit of goods and services, reduction of energy consumption and greenhouse gases emission, and land use, and increasing the use of green transportation. The government can contribute to the implementation and execution of affordable, economically feasible, environment friendly and efficient transportation system by transportation planning and design, laws and policies. Transportation planning and design have a direct influence on development patterns, travel mode choices, infrastructure costs, redevelopment potential, health of natural resources, and other community concerns. Recommendations and solutions to achieve sustainable transportation in Riyad city are presented below.

Parking: Evidence shows that the parking management can minimize the use of private motor vehicles. The decreasing of length and availability of parking and the increasing of parking cost can be an 
effective solution in fighting the increase of using of private vehicle in Riyad.

Congestion: it is known that the congestion traffic issues can be solved by increasing the road capacity and by expanding the network and build on new roads. However, this solution is not effective since it is pricey and costly and it requires more space that cannot be always available. The use of Traffic Management (TSM) technique and more specifically the Ram Metering (RM) that focuses on controlling merging vehicles onto the freeway and this minimize the freeway congestion. The advantage of this technique is not costly and it improves the safety without adding new lanes on the highway [20].

Hybrid electric vehicles (HEVs): present a fuelefficient solution that aims to decrease the fuel consumption and thus the gas emissions. HEVs incorporate an electric engine with the conventional internal combustion motor. Nevertheless, the use of HEVs in the Kingdom is spindly, mainly owing to unfamiliarity of the efficacity of HEVs in saving fuel consumption and minimizing gas emissions besides the cost of HEVs that is considered expensive compared to the conventional cars.

Adaptation of cycling and walking infrastructure with the climate change: Riyad city is characterized by hot desert climate that affects the cyclists and pedestrians and drive them to use private cars. Development of pleasant and agreeable outside environment for cyclists and pedestrians can play a significant role in emboldening people to walk and cycle. Many resilient actions can be performed to improve the cycling and walking infrastructure such as increasing greenery, green roof and shade areas for and nearness pedestrians areas and cycle lines in order to decrease the outside temperature, increase cooling and decrease heat exposure. Also, using high solar reflectance and cooling walkway in cycling lines and pedestrianized areas. It should be mentioned that preferably the integration of climate adaptation for cycling and walking should be from the beginning of the project.

Enabling environment/improving public transport: A creation of enabling environment is crucial for a successful and useful used of public transport. It starts by creating a complete and convenient infrastructure network such as building LRT lines, bus lanes and bus stops. Besides, effective regulations are essential for a smooth transition from private to public transportation. Also, providing high quality service by using information technology systems that contain electronic ticketing systems, destination signage, datacommunication. Moreover, publicizing the culture of public transport via social media, local media and community campaigns to spread awareness on the advantages of the use of public transports.

Involve and encourage citizens in activities to promote sustainable transportation solutions by spreading knowledge on the importance of the integration of sustainable transportation on the human and environment.

Preventing death and injury by car crashes: many actions can be taken in order to decrease the high number of injuries and deaths. The disease, ageing, videophones should be categorized among the main causes of crashes. Besides, the road safety should be integrated in the road design and infrastructure to make the road safer for vehicles drivers, cyclists, and pedestrians.

Reinforce diversified financing sources to support the projects and initiatives in the field of sustainable transportation.

Foster intelligent transport systems (ITS): ITS provide prior information regarding the traffic in order to reduce the traffic problems, saving time and boost the safety and efficiency of road.

\section{References}

1. Rodrigue, J.-P., C. Comtois, and B. Slack, The Geography of Transport Systems. 2016. 1-440.

2. Middleton, D.A., Growth and expansion in post-war urban design strategies: CA Doxiadis and the first strategic plan for Riyadh Saudi Arabia (1968-1972). 2009, Georgia Institute of Technology.

3. Alkhayyal, Z., Urban Growth Change Analysis of Riyadh, Saudi Arab ia: 2005-2015. Saint Mary's University of Minnesota University Central Services Press, 2017. 20: p. 10pp.

4. Alkhayyal, Z., Urban Growth Change Analysis of Riyadh, Saudi Arabia: 2005-2015. Saint Mary's University of Minnesota University Central Services Press, 2017. 20: p. 10.

5. Hall, P., Cities in Civilization: Culture, Technology and Urban Order. London: Weidenfeld and Nicolson. Creative Cities and Economic Development. Urban Studies, 1998. 4: p. 639-649.

6. Pichler-Milanović, N., European urban sprawl: sustainability, cultures of (anti) urbanism and"hybrid cityscapes. Dela, 2007. 27: p. 101-133.

7. Macrotrends, Riyadh, Saudi Arabia Metro Area Population 1950-2020. 2020.

8. Litman, T., Developing indicators for sustainable and livable transport planning. Victoria Transport Policy Institute, 2015: p. 250-360.

9. Al-Mosaind, M. The effect of changes in land use distribution on travel patterns in Riyadh, Saudi Arabia. in Conference of Planning for Cities in the 21st Century: Opportunities and Challenges (WPSC). Shanghai, China. 2001.

10. Al-Hathloul, S., Riyadh architecture in one hundred years. Darat al-Funun. Amman, Jordan, 2002.

11. Numbeo. Traffid in Riyad, Saudi Arabia. 2020.

12. Contributor, U.-H.C.T.a., Saudi Cities Report 2019. 2019: Riyad.

13. Al-Majhad, H.G., et al., A traffic congestion framework for smart riyadh city based on iot services. International Journal of Advanced Computer Science and Applications, 2018. 9(4): p. 292-303.

14. Mansuri, F.A., et al., Road safety and road traffic accidents in Saudi Arabia: A systematic review of 
existing evidence. Saudi medical journal, 2015. 36(4): p. 418.

15. Aldalbahi, M. and G. Walker, Riyadh transportation history and developing vision. Procedia-Social and Behavioral Sciences, 2016. 1: p. 17-163.

16. Alsaif, K.A., et al., Noise mapping of Riyadh city using real measurements and GPS data.

17. Koushki, P.A., L.F. Cohn, and A.A. Felimban, Urban traffic noise in Riyadh, Saudi Arabia: Perceptions and attitudes. Journal of transportation engineering, 1993. 119(5): p. 751-762.

18. Alharbi, B., M. Pasha, and N. Tapper, Assessment of ambient air quality in Riyadh City, Saudi Arabia. Current World Environment, 2014. 9(2): p. 227.

19. Modaihsh, A.S., et al., The air quality, characterization of polycyclic aromatic hydrocarbon, organic carbon, and diurnal variation of particulate matter over Riyadh City. Journal of Environmental Protection, 2016. 7(9): p. 1198-1209.

20. Neudorff, L.G., et al., Freeway management and operations handbook. 2003, United States. Federal Highway Administration. Office of Transportation .... 